\title{
Scalability of regional climate change in Europe for high-end scenarios
}

\author{
O. B. Christensen ${ }^{1, *}$, S. Yang ${ }^{1}$, F. Boberg ${ }^{1}$, C. Fox Maule ${ }^{1}$, P. Thejll, M. Olesen ${ }^{1}$, \\ M. Drews ${ }^{2}$, H. J. D. Sørup ${ }^{1,3}$, J. H. Christensen ${ }^{1}$ \\ ${ }^{1}$ Danish Meteorological Institute, Copenhagen, Denmark \\ ${ }^{2}$ DTU Management Engineering, Danish Technical University, Roskilde, Denmark \\ ${ }^{3}$ DTU Environment, Danish Technical University, Lyngby, Denmark
}

\begin{abstract}
With the help of a simulation using the global circulation model (GCM) EC-Earth, downscaled over Europe with the regional model DMI-HIRHAM5 at a $25 \mathrm{~km}$ grid point distance, we investigated regional climate change corresponding to $6^{\circ} \mathrm{C}$ of global warming to investigate whether regional climate change generally scales with global temperature even for very high levels of global warming. Through a complementary analysis of CMIP5 GCM results, we estimated the time at which this temperature may be reached; this warming could be reached in the first half of the 22nd century provided that future emissions are close to the RCP8.5 emission scenario. We investigated the extent to which pattern scaling holds, i.e. the approximation that the amplitude of any climate change will be approximately proportional to the amount of global warming. We address this question through a comparison of climate change results from downscaling simulations over the same integration domain, but for different driving and regional models and scenarios, mostly from the EU ENSEMBLES project. For almost all quantities investigated, pattern scaling seemed to apply to the $6^{\circ}$ simulation. This indicates that the single $6^{\circ}$ simulation in question is not an outlier with respect to these quantities, and that conclusions based on this simulation would probably correspond to conclusions drawn from ensemble simulations of such a scenario. In the case of very extreme precipitation, the changes in the $6^{\circ}$ simulation are larger than would be expected from a linear behaviour. Conversely, the fact that the many model results follow a linear relationship for a large number of variables and areas confirms that the pattern scaling approximation is sound for the fields investigated, with the identified possible exceptions of high extremes of e.g. daily precipitation and maximum temperature.
\end{abstract}

KEY WORDS: Pattern scaling $\cdot$ Extremes $\cdot$ Ensembles

\section{INTRODUCTION}

Actual greenhouse gas emissions are increasing and currently follow the highest emission scenarios considered by modellers (e.g. Peters et al. 2013, Le Quéré et al. 2014). This has prompted several recent studies to suggest that it may be an immense challenge to reach the ' $2{ }^{\circ}$ goal' (e.g. Anderson \& Bows 2011, Peters et al. 2013, Stocker 2013). In the continued absence of sufficient efforts to stabilise atmospheric concentrations of greenhouse gases, it is in fact

${ }^{*}$ Corresponding author: obc@dmi.dk likely that the average global temperature rise may approach $6^{\circ} \mathrm{C}$ relative to the pre-industrial climate in the long term (or about $4^{\circ} \mathrm{C}$ in 2100 ) if current emission trends persist (e.g. Solomon et al. 2007).

The climate modelling community has been investigating high-end climate change scenarios for decades, mostly in an attempt to obtain results of climate change projections having a high signal-tonoise ratio in order to avoid feeding low-signal-to noise results to impacts models. This aim, to some extent, drove large-scale efforts such as PRUDENCE

() The authors 2015. Open Access under Creative Commons by Attribution Licence. Use, distribution and reproduction are unrestricted. Authors and original publication must be credited. 
(Christensen \& Christensen 2007) and ENSEMBLES (van der Linden \& Mitchell 2009). The impacts community has also given attention to high-end scenarios, particularly for high-impact risks. For example, a warming of $6^{\circ} \mathrm{C}$ has been translated into sea level rise that will affect coastal defence plans (Katsman et al. 2011) and raises safety issues related to the construction of new nuclear plants (Wilby et al. 2011).

Using a small perturbed-physics global circulation model (GCM) ensemble driven by the Special Report on Emissions Scenarios (SRES) A1FI scenario (Nakićenović et al. 2000) as well as the CMIP3 multimodel ensemble, Betts et al. (2011) found that a global mean warming of approximately $4^{\circ} \mathrm{C}$ could already be realised around 2070 (see also Joshi et al. 2011). Similarly, the most recent assessment from the Intergovernmental Panel on Climate Change (IPCC; Stocker et al. 2013) concluded that globally averaged surface temperatures could rise to very high levels by the end of the 21st century, if the world evolves according to a non-mitigation scenario with continuing rise in greenhouse gas emissions, likely between 2.6 and $4.8^{\circ} \mathrm{C}(2081-2100$ relative to $1986-2005)$.

The selection of scenarios for numerical simulations, e.g. the choice of particular SRES or representative concentration pathway (RCP) emission scenarios to be simulated with models, evidently has a large influence on the span of global temperature change being considered. Therefore, it is of great interest to study what the world might look like in a state-ofthe-art climate model in situations with considerably stronger anthropogenic climate change than usually considered. Only a few dedicated studies have specifically addressed the higher-end range of climate change scenarios, and these have mostly had a global focus. One such attempt to address the consequences of a world evolving according to a high-end emission scenarios was provided by New (2011) and elaborated in a thematic issue of the Philosophical Transactions of the Royal Society (e.g. New et al. 2011, Sanderson et al. 2011). Most of the climate scenarios analysed were based on IPCC SRES A1FI and A2. Here, the plausible societal consequences were discussed, but without going into an actual assessment of the future climate at the regional scale. In the following, we aim to address this issue, and we offer a single numerical simulation at the regional scale for Europe. Since a single simulation is clearly insufficient for a robust analysis of climate change effects (e.g. Sloth Madsen et al. 2012), we anchor our analysis of this single $6^{\circ} \mathrm{C}$ simulation in the context of multi-model ensemble realisations of less extreme warming scenarios in order to argue the plausibility of the resulting climate. In this context, we analysed the extent to which various climate parameters exhibit 'pattern scaling', i.e. whether the change in the relevant parameter is approximately proportional to the change in global temperature.

Pattern scaling has previously been used in several contexts. It is an approximation that has been explicitly suggested in the description of the RCPs (Moss et al. 2010) as a method for deriving impact-relevant regional projections for scenarios that have not been simulated by global and regional climate models. This well-established technique (e.g. Santer et al. 1990, Huntingford \& Cox 2000) has been applied regularly in integrated assessment models (Moss et al. 2010). Also, Sanderson et al. (2011) analysed the spatial patterns of regional temperature and precipitation changes in global projections driven by the SRES A2 scenario, where about half of the model simulations are classified as high-end projections corresponding to a warming of $4^{\circ} \mathrm{C}$ or more by the end of this century relative to the pre-industrial level. In their study, Sanderson et al. (2011) found the largescale patterns of temperature and precipitation (scaled to $4^{\circ} \mathrm{C}$ global warming) to be similar in the high-end and non-high-end projections with small regional differences.

Similarly, while projections from IPCC's Fourth Assessment Report (AR4) (Solomon et al. 2007) clearly suggest that levels of warming far exceeding $4^{\circ} \mathrm{C}$ are possible by the end of the 21st century, the highest emission scenario considered (SRES A1FI) at that time was not examined with complex GCMs, and similarly, the uncertainties in climate-carbon-cycle feedbacks were not included in the main set of GCMs. Instead, like the Third Assessment Report (Houghton et al. 2001), AR4 used a combination of pattern scaling (Mitchell 2003), climate models of intermediate complexity (Claussen et al. 2002) and expert elicitation to provide an estimate of the full range of climate projections corresponding to the SRES scenarios, including the A1FI. Although these techniques are valid for low to moderate levels of warming, it was not investigated whether various climate parameters like temperature, precipitation, wind, etc. are also scalable at much higher global warming signals, where nonlinearity could be expected to play a role, particularly at finer regional scales (e.g. Lambert et al. 2013).

In this study, we investigated the regional response over Europe to a global mean warming of approximately $6^{\circ} \mathrm{C}$ as captured by the DMI-HIRHAM5 (hereafter just referred to as HIRHAM5) regional climate model (RCM), driven by the coupled GCM EC-Earth. In absolute terms, this $6^{\circ} \mathrm{C}$ warmer climate is very 
different from the present one both globally and regionally; the warming is considerably larger than estimates of the amplitude of the glacial-interglacial cycles of Earth. Patterns of change in this simulation are, however, quite similar to simulated future climate corresponding to lower warming. The paper presents aspects of the climate in Scandinavia and the whole of Europe based on this simulation. We put the results in the context of simulations with the same global and RCM combination under weaker climate change, using shorter projection horizons and weaker emission scenarios, and examine whether regional climate change in the $6^{\circ} \mathrm{C}$ simulation scales in the same way with global temperature change as these simulations. In order to make the study more robust, we moreover complemented our EC-EarthHIRHAM5 simulations with similar simulations from the ENSEMBLES (van der Linden \& Mitchell 2009) database.

\section{METHODS}

\subsection{Model setup and data}

To achieve a scenario wherein the global mean warming is $6^{\circ} \mathrm{C}$ warmer than the pre-industrial level, we performed a benchmark CMIP experiment of idealized $1 \%$ per year $\mathrm{CO}_{2}$ increase using the EC-Earth model. EC-Earth is a state-of-the-art global climate model system developed by the EC-Earth consortium (Hazeleger et al. 2012). The model version used in this study and in the CMIP5 experiments is configured at an enhanced atmospheric resolution of T159 $(125 \times 125 \mathrm{~km}$ linear grid spacing) and 62 vertical layers, and an ocean resolution at about $1^{\circ} \times 1^{\circ}$ with a meridional refinement down to $1 / 3^{\circ}$ at the equator and 42 vertical layers. The climate sensitivity of the EC-Earth model is typical for the CMIP5 multi-model ensemble (see e.g. www.combine-project.eu/fileadmin/ user_upload/combine/dels/D7.2.pdf).

The EC-Earth simulation was initialized from a pre-industrial control experiment, and the atmospheric $\mathrm{CO}_{2}$ concentration was prescribed to increase at $1 \%$ per year from the pre-industrial value (285 ppm) until 5 times the initial level was reached, and then kept constant afterwards. The simulation was $250 \mathrm{yr}$ long, with all other forcings kept at the pre-industrial level. The simulated global mean surface temperature increases as long as the $\mathrm{CO}_{2}$ concentration increases, and continues to slowly increase for several decades even after the $\mathrm{CO}_{2}$ concentration stops growing. It gradually stabilises at a level of about $6.5^{\circ} \mathrm{C}$ above the pre-industrial level (defined as the simulated period 1881-1910) towards the end of the simulation.

To resolve regional to local scale features of the $6^{\circ} \mathrm{C}$ EC-Earth simulation, we dynamically downscaled 2 time slices of this simulation: a control period covering 1976-2005 and the last $30 \mathrm{yr}$ of the simulation using the atmospheric regional climate model HIRHAM5 (Christensen et al. 2006); the global temperature difference between these periods is $6.2^{\circ} \mathrm{C}$. Similarly, we used HIRHAM5 to dynamically downscale EC-Earth simulations for a time-slice covering 2071-2099 for the RCP4.5 scenario, and to carry out a transient simulation for 1961-2100 for RCP8.5. In the transient simulation, 1961-2005 is driven with historical forcing and 2006-2100 by forcing according to RCP $8.5 ; 3$ different non-overlapping periods are used in this study: 20112040, 2041-2070 and 2071-2099. The downscaling is done on a rotated longitude-latitude grid covering Europe, the Mediterranean area and the North Atlantic, with a horizontal grid spacing of about $25 \mathrm{~km}$, and 31 atmospheric vertical layers. This is the same domain and grid as used in the ENSEMBLES regional simulations (van der Linden \& Mitchell 2009, Christensen et al. 2010), cf. Fig. 4 for ease of comparison with these simulations. Hence, by design, all RCM simulations in the present study use approximately identical integration areas and horizontal resolution, which means that variations of these parameters will not influence the results. A total of 3 simulations using HIRHAM5 on this grid are presently available in the ENSEMBLES RCM database. Three transient simulations running under the SRES A1B scenario using 3 different GCMs, viz. ECHAM5 (1951-2100), ARPEGE (1951-2100) and BCM (1961-2099), have previously been downscaled with HIRHAM5. The simulations are summarised in Table 1.

In addition to the ENSEMBLES simulations, we used results from the CMIP5 data base (Taylor et al. 2012) used in AR5, in order to demonstrate that the high-end scenarios are formally realisable, and to characterize possible time frames for exceeding the $6^{\circ} \mathrm{C}$ threshold.

\subsection{Pattern scaling}

The pattern scaling concept we explore builds on the approach also adopted by AR5 (e.g. Collins et al. 2013). The basic idea of pattern scaling is that climate change can be described as geographical patterns of projected changes in climate variables, which vary according to a general scaling parameter depending 
Table 1. Overview of the regional climate model (RCM) simulations considered in the analysis with the corresponding global circulation model (GCM) global warming values listed. NS: not simulated

\begin{tabular}{|c|c|c|c|c|c|}
\hline GCM & $\mathrm{RCM}$ & Scenario & $\begin{array}{c}\Delta \mathrm{T}_{\text {glob } 2011-2040} \\
\left({ }^{\circ} \mathrm{C}\right)\end{array}$ & $\begin{array}{c}\Delta \mathrm{T}_{\text {glob 2041-2070 }} \\
\left({ }^{\circ} \mathrm{C}\right)\end{array}$ & $\begin{array}{c}\Delta \mathrm{T}_{\text {glob 2071-2100 }} \\
\left({ }^{\circ} \mathrm{C}\right)\end{array}$ \\
\hline EC-EARTH & HIRHAM5 & RCP 4.5 & NS & NS & 1.90 \\
\hline EC-EARTH & HIRHAM5 & RCP 8.5 & 0.86 & 2.00 & 3.43 \\
\hline EC-EARTH & HIRHAM5 & $6 \mathrm{deg}$ & NS & NS & 6.20 \\
\hline ECHAM & HIRHAM5 & $\mathrm{A} 1 \mathrm{~B}$ & 0.66 & 1.75 & 2.93 \\
\hline ECHAM & $\operatorname{RegCM}$ & A1B & 0.66 & 1.75 & 2.93 \\
\hline ECHAM & RACMO & A1B & 0.66 & 1.75 & 2.93 \\
\hline ECHAM & REMO & A1B & 0.66 & 1.75 & 2.93 \\
\hline ECHAM & RCA & A1B & 0.66 & 1.75 & 2.93 \\
\hline HadCM3Q0 & CLM & A1B & 1.05 & 2.08 & 3.00 \\
\hline HadCM3Q0 & HadRM3Q0 & A1B & 1.05 & 2.08 & 3.00 \\
\hline HadCM3Q3 & HadRM3Q3 & A1B & 0.88 & 1.67 & 2.49 \\
\hline HadCM3Q3 & RCA & A1B & 0.88 & 1.67 & 2.40 \\
\hline HadCM3Q16 & RCA & A1B & 1.28 & 2.56 & 3.94 \\
\hline HadCM3Q16 & HadRM3Q16 & A1B & 1.28 & 2.56 & 3.94 \\
\hline $\mathrm{BCM}$ & HIRHAM5 & A1B & 0.55 & 1.59 & 2.41 \\
\hline $\mathrm{BCM}$ & $\mathrm{RCA}$ & A1B & 0.55 & 1.59 & 2.41 \\
\hline ARPEGE & HIRHAM5 & A1B & 0.83 & 1.81 & 2.60 \\
\hline ARPEGE & Aladin & A1B & 0.83 & 1.81 & 2.60 \\
\hline
\end{tabular}

on scenarios and time horizons. Specifically, we used global average temperature change of the driving GCM as a general scaling parameter and studied the extent to which various forms of climate change across the ensemble of modelled periods scale with this.

There are known limitations to this approach besides degradation of its performance as the regional scale of interest becomes finer in the presence of regionally specific forcings. Recent work (Shiogama et al. 2010a,b) has revealed a dependence of precipitation on the scenario, due to precipitation being sensitive to scenario-dependent regional changes in carbon aerosol loads. In their study, there are major differences in black and organic carbon aerosol forcing between the emissions scenarios investigated. This is a behaviour which is linked to a more general limitation of pattern scaling, which appears to break down if aerosol forcing is significant (e.g. Collins et al. 2013). Likewise, for quantities with long characteristic time scales, the validity of pattern scaling is questionable; changes in variables with a large inertia (such as sea level, vegetation dynamics, glacier properties, permafrost conditions, sea ice volume and extent) depend on their history of change, and therefore not only on current global warming. Also, various properties of extreme events are connected through heavily non-linear relationships; they cannot all be linear with global temperature simultaneously.
It is, however, a reasonable first approximation to assume that pattern scaling holds in the sense that interpolation in time and between different levels of radiative forcings often reproduces direct model results of the same quantities (Mitchell 2003, Ruosteenoja et al. 2007, Lustenberger et al. 2014). In this study, we go beyond what has traditionally been explored by investigating similar relations for other variables and by widening the concept to include data from multiple time windows and an ensemble of models. The latter will tend to mask the role of individual models' specific responses to local drivers (e.g. aerosols). In the following, we focus on results for the entire European domain as well as for Scandinavia only; in all cases, only land points in the RCM simulations are considered. The fields that we investigated are seasonal averages of temperature and precipitation, annual maxima of temperature and various precipitation extremes. The latter is analysed both in the context of directly modelled percentiles and through a Gumbel fit of pointwise annual maxima of daily precipitation. For each field and area, linear regression lines are derived from the collection of 49 climate change results ( 3 sub-periods for 16 transient simulations plus 1 time-slice RCP4.5 simulation) plotted as a function of the corresponding global warming (cf. Figs. 5-8). The remaining $6^{\circ} \mathrm{C}$ result is compared to this line. To ascertain whether the $6^{\circ} \mathrm{C}$ simulation complies with the pat- 
tern scaling approximation, we analysed the uncertainties in the following way.

Each of the simulated $30 \mathrm{yr}$ future periods corresponds to 1 point in the graph, with the global warming of the driving GCM along the $x$-axis and the change for the field in question along the $y$-axis. For each figure, we calculated the best linear fit to all the points except the $6^{\circ} \mathrm{C}$ simulation, as we were interested in seeing how the $6^{\circ} \mathrm{C}$ simulation is positioned relative to the best-fit line based on the remaining ensemble. For all the fields analysed in this manner, different error bars are calculated, indicated by colour coding.

The black error bar on the line drawn at about $6^{\circ} \mathrm{C}$ global warming represents $\pm 1 \mathrm{SE}$ of the value of the regression line there. This is calculated by re-sampling of the model values (excluding the $6^{\circ} \mathrm{C}$ model) using a bootstrap with replacement routine (4000 iterations).

The red error bars on the value of the $6^{\circ} \mathrm{C}$ simulation represent $\pm 1 \mathrm{SE}$ of the point value. This is also determined by the bootstrapping mentioned above - for each bootstrap sample, the standard deviation of the distance from the regression line is determined and tabulated. At the end of all 4000 samplings, the mean of the standard deviations is taken and used as the estimate of the standard error of the point value.

The joint error is calculated as the square root of the sum of the squared error estimates for the line position and for the point position. This approach works if the residuals, from which the standard error on the point position is estimated, are normally distributed and independent. We tested whether this was the case by applying a different method and found that the 2 approaches gave the same joint error. The alternative method was based on sums of the deviation of the $6^{\circ} \mathrm{C}$ point from the bootstrap-sample regression line and a randomly drawn residual from the current bootstrap. In the case of the residuals being normally distributed and being independent, this will give the same joint error estimate, which was the case within a few percent. Had the 2 estimates of the joint error differed, the latter approach would have been used exclusively. Finally, we estimate the significance of the deviation of the $6^{\circ} \mathrm{C}$ model from the regression line. This is indicated by a 'delta value' (given in the lower corner of each panel) expressing the deviation of the $6^{\circ} \mathrm{C}$ point from the regression line expressed in units of the joint error estimate. With $|\Delta|$ less than $2 \sigma$, we accept that the $6^{\circ} \mathrm{C}$ point is drawn from the same population as the other points, otherwise we reject this.

\section{RESULTS}

\subsection{Global future climate under $6^{\circ} \mathrm{C}$ warming}

Fig. 1 shows the 30 yr averages of annual mean surface temperature and precipitation in the $6^{\circ} \mathrm{C}$ scenario (cf. Section 2) for the last $30 \mathrm{yr}$ of the simulation. The top panels show absolute values of the projections, whereas the bottom panels show changes relative to a historical (1976-2005) simulation by ECEarth. At this climate $\left(6^{\circ} \mathrm{C}\right.$ warmer than the preindustrial level), the surface temperature is more than $2^{\circ} \mathrm{C}$ higher than the present day (1976-2005) everywhere on the globe. As would be expected, the warming is stronger over land and strongest in the Arctic where the annual mean surface temperature increases by more than $15^{\circ} \mathrm{C}$. In response to the warming, the precipitation in the Intertropical Convergence Zone and the Indian monsoon region increases significantly in an area around the Equator, accompanied by a decrease of precipitation in the subtropics. At high latitudes and over the North Pacific, precipitation increases. The projected patterns of temperature and precipitation changes in the simulation are quite similar to the projected changes of the RCP8.5 scenario of an ensemble of CMIP5 models presented by Stocker et al. (2013); however, the amplitude in the features studied here are evidently stronger.

\subsection{When will we reach $6^{\circ} \mathrm{C}$ ?}

The way it has been constructed, the present $6^{\circ} \mathrm{C}$ EC-Earth simulation does not claim to correspond to any realistic socio-economic scenario for the 21st century, nor can it be used to determine the time at which a $6^{\circ} \mathrm{C}$ warming could be reached in reality. To try to estimate a realistic timing, we therefore instead looked at the currently available large multi-model ensemble of CMIP5 simulations (Taylor et al. 2012). We found that none of the simulations for the RCP6.0, RCP4.5 and RCP2.6 scenarios reach $6^{\circ} \mathrm{C}$ of global warming, not even those simulations that extend to the year 2300 (which is 1, 10 and 9 simulations for the different scenarios, respectively; see also Fig. 12.40 in Collins et al. 2013). For the RCP8.5 scenario, however, several simulations reach $6^{\circ} \mathrm{C}$ with respect to the pre-industrial level (18811910). Fig. 2 shows the temporal evolution in global annual mean temperature for the 38 CMIP5 members for this scenario; 9 of these are continued until 2300; the remaining simulations, including EC- 

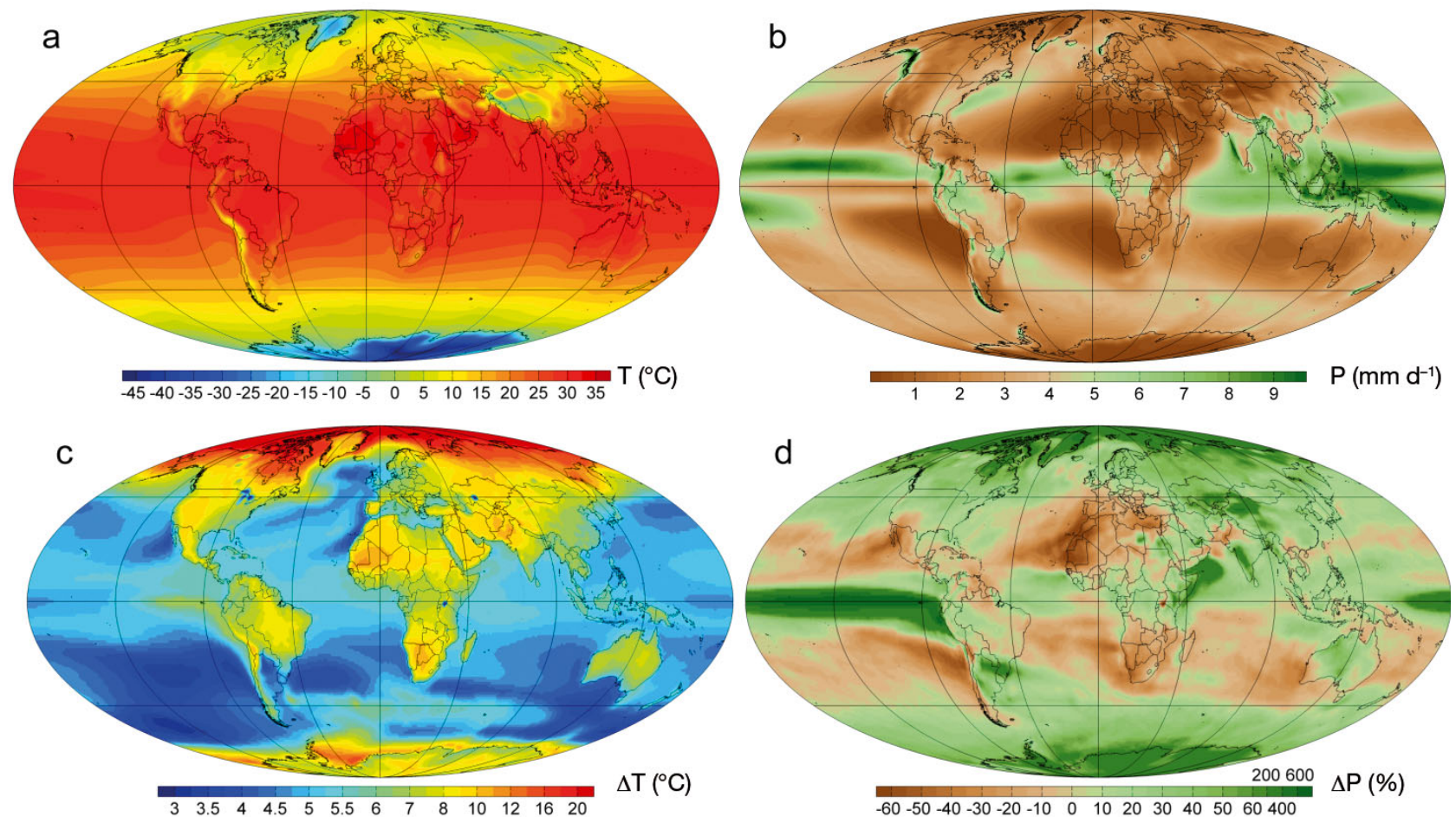

Fig. 1. 30 yr mean annual (a) surface air temperature and (b) precipitation in the $6^{\circ} \mathrm{C}$ simulation and (c,d) their changes corresponding to a global warming of $6^{\circ} \mathrm{C}$

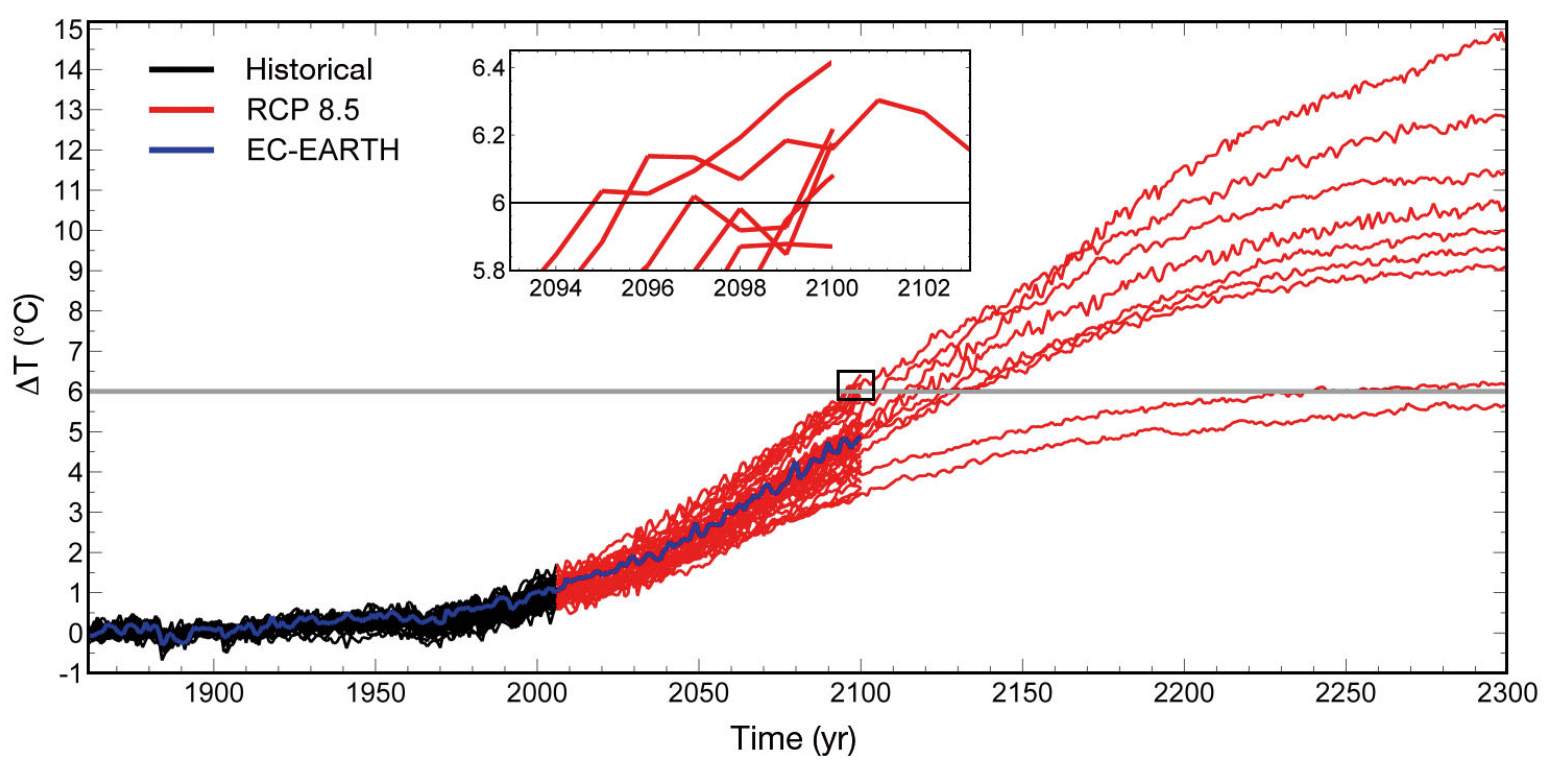

Fig. 2. Global annual mean temperature for the RCP8.5 scenario of the 38 CMIP5 members compared to the pre-industrial level from 1881-1910; 29 simulations end in 2100, 9 are continued to 2300. Based on this figure, the 9 long simulations represent the full ensemble well, with members of both high and low climate sensitivity

Earth, end in 2100. Of the $29 \mathrm{GCM}$ simulations that end in 2100,5 reach $6^{\circ} \mathrm{C}$ before or in 2100 , and of the 9 simulations that continue until 2300, 8 reach $6^{\circ} \mathrm{C}$. In general, the different paths of the global temperature change indicated by GCMs are quite different, with changes towards 2300 ranging between $5.5^{\circ} \mathrm{C}$ and $15^{\circ} \mathrm{C}$ global warming compared to pre-industrial temperature. The earliest time at which any model reaches $6^{\circ} \mathrm{C}$ is 2095 . That said, recent studies suggest that the upper end of the 
range of CMIP5 climate model projections is inconsistent with past warming (Stott et al. 2013), and models showing a particular non-linear sensitivity to present-day warming appear to exaggerate the warm-season temperature response (Boberg \& Christensen 2012, Christensen \& Boberg 2012). It is therefore probable that the very earliest crossings of the threshold could be due to an unrealistically high climate sensitivity. Regarding EC-Earth, we find that prior to 2100 it follows a group of long-simulation GCMs which reach $6^{\circ} \mathrm{C}$ between 2113 and 2132, indicating that EC-Earth would probably do the same.

Since the 9 models that continue past 2100 seem to be rather representative of the full ensemble, our best estimate of a timing for $6^{\circ} \mathrm{C}$ of warming would be the first half of the 22nd century, provided that actual greenhouse gas emissions would follow RCP8.5 approximately.

\subsection{European future climate}

Fig. 3 shows the absolute changes in seasonal mean temperature and the relative changes in seasonal mean precipitation for Europe compared to the present day (1976-2005) for both summer (JJA) and winter (DJF) for the $6^{\circ} \mathrm{C}$ simulation, downscaled by HIRHAM5. Winter temperatures increase with amounts from about $5^{\circ} \mathrm{C}$ in western and southern Europe (British Isles, Iberian Peninsula, France) to more than $9^{\circ} \mathrm{C}$ in the northeast (northern Finland, western Russia). In summer, the largest temperature change of more than $9^{\circ} \mathrm{C}$ is found in the Iberian Peninsula and southern France; large changes of $7-8^{\circ} \mathrm{C}$ are also found along the northern coast of the Scandinavian Peninsula. The lowest temperature in- creases of about $5-6^{\circ} \mathrm{C}$ are found in most of Northern Europe, centred on the Baltic Sea, and also including the British Isles. The geographical patterns of these changes appear robust when comparing to the projected changes in Europe under a $2^{\circ} \mathrm{C}$ global warming presented in a recent paper by Vautard et al. (2014) based on an ensemble of simulations from the ENSEMBLES project; only the amplitude of change seems much higher for the simulation with $6^{\circ} \mathrm{C}$ of global warming in a visual comparison. For precipitation, the winter mean precipitation increases in large parts of Europe, primarily north of $47^{\circ} \mathrm{N}$, with the largest changes of more than $60 \%$ increase in the north and east of the Baltic Sea. The largest decrease of $30-50 \%$ occurs in the Iberian Peninsula and along the Mediterranean coastline. In summer, the band dividing wetting from drying shifts northward; increases of about $20-40 \%$ are only found on the Scandinavian Peninsula, in Finland, the Baltic countries and in Russia, with the highest values in the Norwegian mountains. The largest decreases of $50-60 \%$ in seasonal mean precipitation occur in the Iberian Peninsula, southern Italy, Albania, Greece and Turkey. In summary, EC-Earth-HIRHAM5 projects that particularly in winter, north-eastern Europe could get a much warmer and wetter climate, whereas in summer, the largest changes occur in the Iberian Peninsula and along the Mediterranean coast with a much warmer and drier climate. The noticeable changes in winter of much warmer and wetter conditions in northeastern Europe are visible even in a $2^{\circ} \mathrm{C}$ warmer world for the ensemble mean of 14 ENSEMBLES RCMs (Vautard et al. 2014). The patterns presented in the RCP8.5 Atlas (Stocker et al. 2013) based on the CMIP5 database also exhibit patterns which resemble those displayed in Fig. 3.
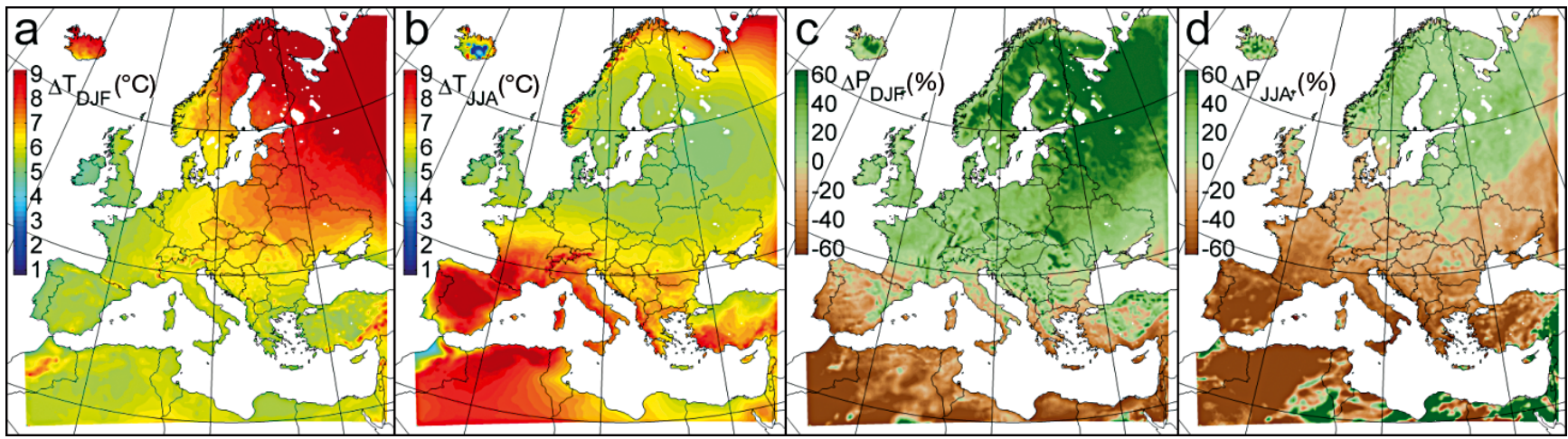

Fig. 3. Changes in seasonal mean (a) winter temperature, (b) summer temperature, (c) winter precipitation and (d) summer precipitation compared to $1976-2005$ for the $6^{\circ} \mathrm{C}$ scenario 


\subsection{Validity of pattern scaling}

To test the validity of regional pattern scaling in Europe, we examined various fields averaged over land points for the 8 regions (Fig. 4) defined in the PRUDENCE project (Christensen \& Christensen 2007). We also investigated the entire region, defined by the combined extent of the 8 regions. Here we present the results of the Scandinavian (SC) and combined (EU) regions (see Figs. 5-8); results for all regions are provided in the Supplement www.int-res.com/ articles/suppl/c064p025_supp.pdf. All changes are calculated relative to a control period of 1976-2005. We will show seasonal mean temperature change, relative precipitation change; changes in 30 yr return values of maximum temperature; relative changes in 95th percentiles of daily precipitation; changes in simulated 30 yr maximum daily precipitation; and changes in parameters of Gumbel functions fitted to annual maximum daily precipitation. As described in Section 2, a total of 49 climate change results are included in our analysis, originating from the ENSEMBLES RCM database (van der Linden \& Mitchell 2009) supplemented by additional simulations with HIRHAM5 in addition to the $6^{\circ} \mathrm{C}$ simulation.

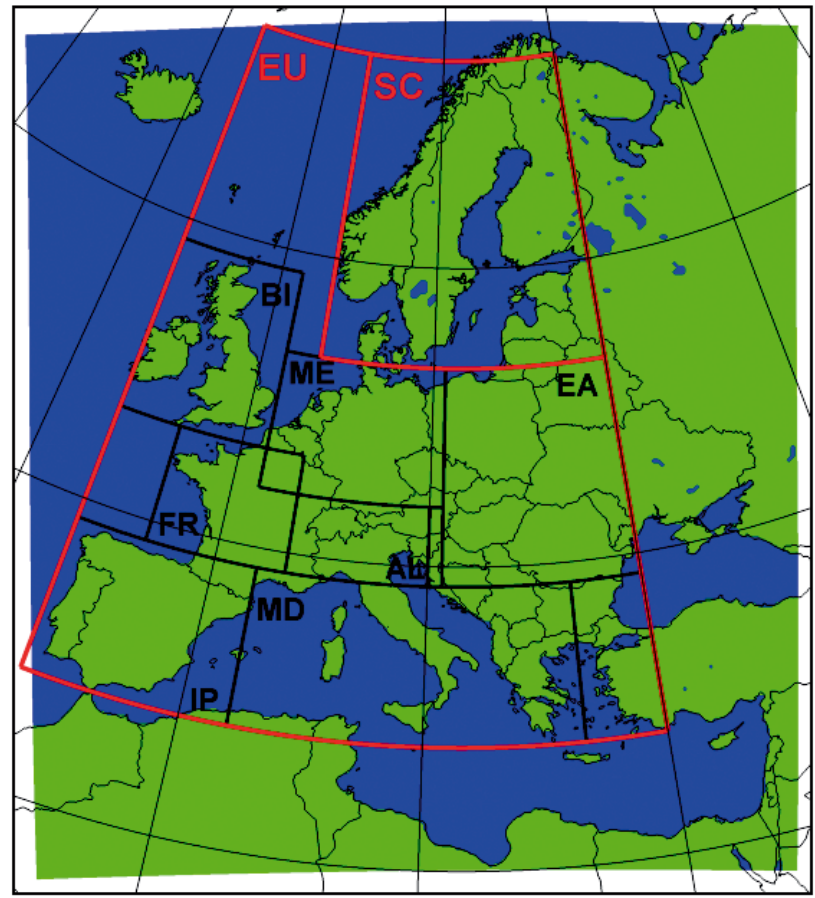

Fig. 4. HIRHAM domain together with the 8 European subregions (SC: Scandinavia, BI: British Isles, ME: Middle Europe, EA: Eastern Europe, FR: France, AL: alpine region, IP: Iberian Peninsula, MD: Mediterranean) and an area encompassing all subregions (EU). This study focussed on land points in SC and EU (highlighted in red)

\subsubsection{Average fields}

Fig. 5 shows results for summer (JJA) and winter (DJF) temperature and precipitation for EU and SC. For precipitation, relative change is shown. For all fields except summer precipitation change in the EU region (Fig. $5 g$ ), $|\Delta|$ is less than $2 \sigma$, indicating that the $6^{\circ} \mathrm{C}$ simulation is drawn from the same population as the other points in most cases. Thus, in these cases, pattern scaling holds. For EU summer precipitation, $|\Delta|$ is $2.09 \sigma$, which we reject, although it is close to the $2 \sigma$ limit.

\subsubsection{Extremes}

To investigate pattern scaling of extreme temperatures, we calculate the change in the 30 yr return value of daily maximum temperature in summer as a function of global mean temperature change. In each grid point, we find the highest daily maximum temperature in each of the $30 \mathrm{yr}$ time slices, and from this determine the change in $30 \mathrm{yr}$ return value in each grid point; these are then averaged over each region. Fig. 6 shows the results for EU and SC. Here we find a $|\Delta|$ value of $0.93 \sigma$ in $\mathrm{SC}$, clearly indicating that the $6^{\circ} \mathrm{C}$ simulation is drawn from the same populations as the remaining simulations. For EU, $|\Delta|$ is $2.51 \sigma$ and thus we reject that the $6^{\circ} \mathrm{C}$ simulation comes from the same population. Therefore, pattern scaling all the way to the $6^{\circ} \mathrm{C}$ experiment does not hold for all regions. Comparing $\mathrm{EU}$ with $\mathrm{SC}$, we find a much higher scatter among the models in SC than in EU. In the other regions investigated (see the Supplement), we find a relatively high scatter also in the British Isles (BI) and Middle Europe (ME), but a relatively low scatter in the Mediterranean (MD) and the Iberian Peninsula (IP). The slopes of the linear fits vary from region to region; for example, we find that the $30 \mathrm{yr}$ return value of summer maximum temperature in $\mathrm{SC}$ is about $7^{\circ} \mathrm{C}$ higher when the global mean temperature has increased with about $6^{\circ} \mathrm{C}$, whereas it is about $11^{\circ} \mathrm{C}$ higher in France (FR).

The change in precipitation extremes represented by the 95th percentile for wet days as well as maximum values is calculated for each point in all regions. A threshold of $1 \mathrm{~mm} \mathrm{~d}^{-1}$ is used to distinguish between wet and dry days (see e.g. Kjellström et al. 2010). The percentiles are calculated for each grid cell in a region and averaged afterwards. Fig. 7 shows the results for the change in 95th percentile and the annual maximum as a function of global mean temperature for SC and EU. In general, the 

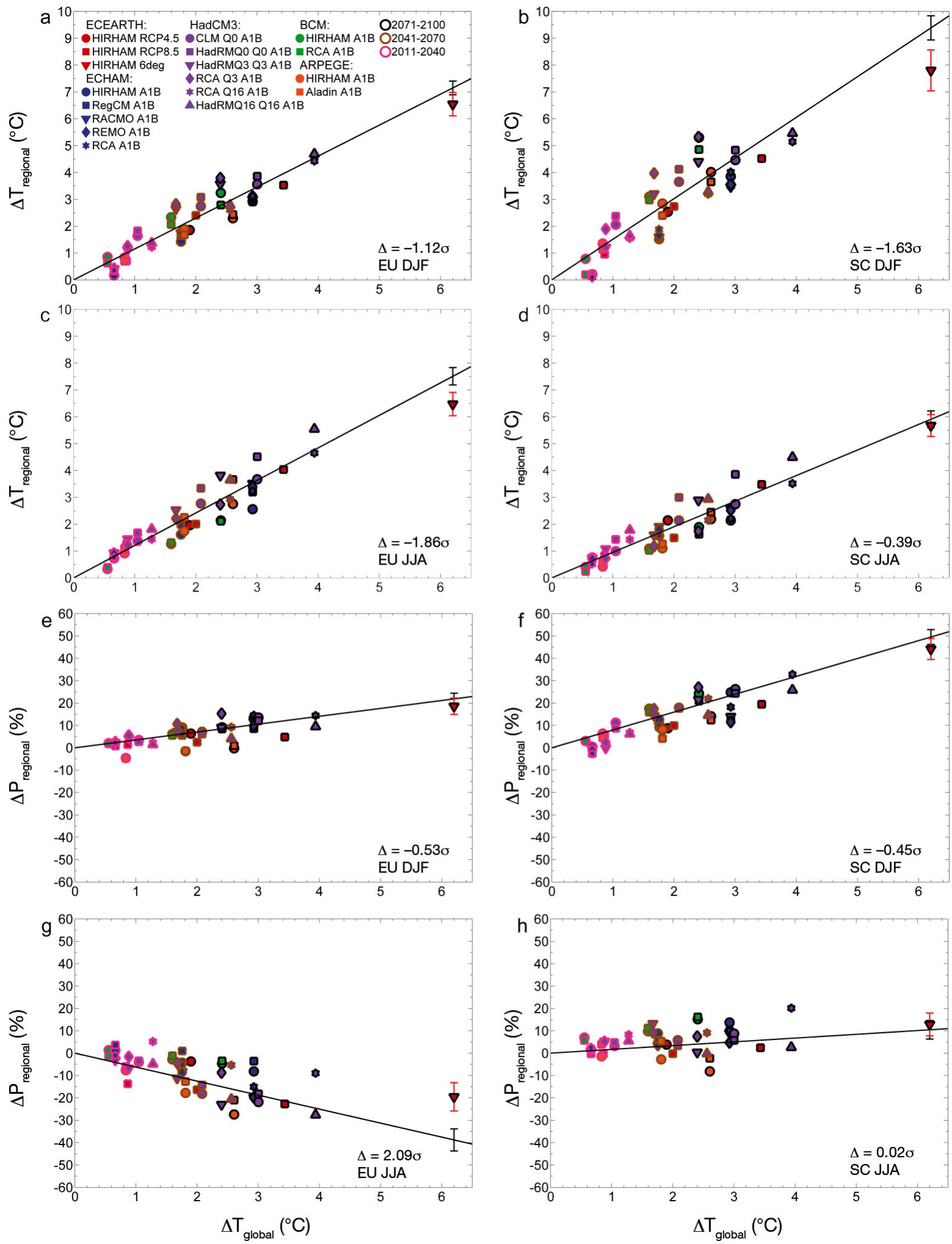

Fig. 5. Change in $(\mathrm{a}, \mathrm{b})$ winter temperature, $(\mathrm{c}, \mathrm{d})$ summer temperature, $(\mathrm{e}, \mathrm{f})$ winter precipitation (relative change) and $(\mathrm{g}, \mathrm{h})$ summer precipitation (relative change) in 8 European regions combined $\left(E U_{;}, a, c, e, g\right)$ and Scandinavia $(S C ; b, d, f, h ; s e e$ Fig. 4) as a function of annual global mean temperature change for the ENSEMBLES A1B simulations and the 3 EC-Earth simulations. For all transient simulations, the average seasonal temperature/precipitation changes of 3 time-slices (30 yr each) are plotted. The solid black line is the linear fit through 0 to all points except the $6^{\circ} \mathrm{C}$ simulation. See text in Section 2.2 for an explanation on the error bars and the $\Delta$ values 

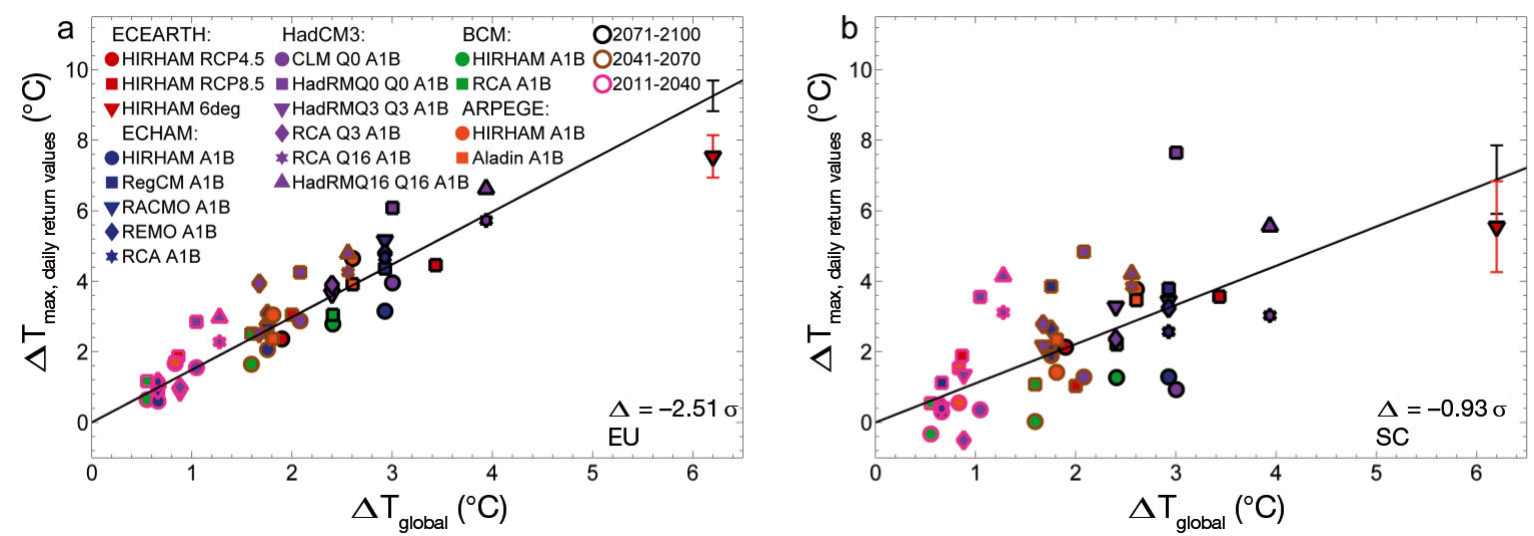

Fig. 6. Change in 30 yr return values of daily maximum summer temperature as a function of global mean annual temperature change in 8 European regions combined (EU) and Scandinavia (SC) (see Fig. 4). The black lines are least-squares fits to the change in the $30 \mathrm{yr}$ return values for all models except the $6^{\circ} \mathrm{C}$ run. See text in Section 2.2 for an explanation on the error bars and the $\Delta$ values
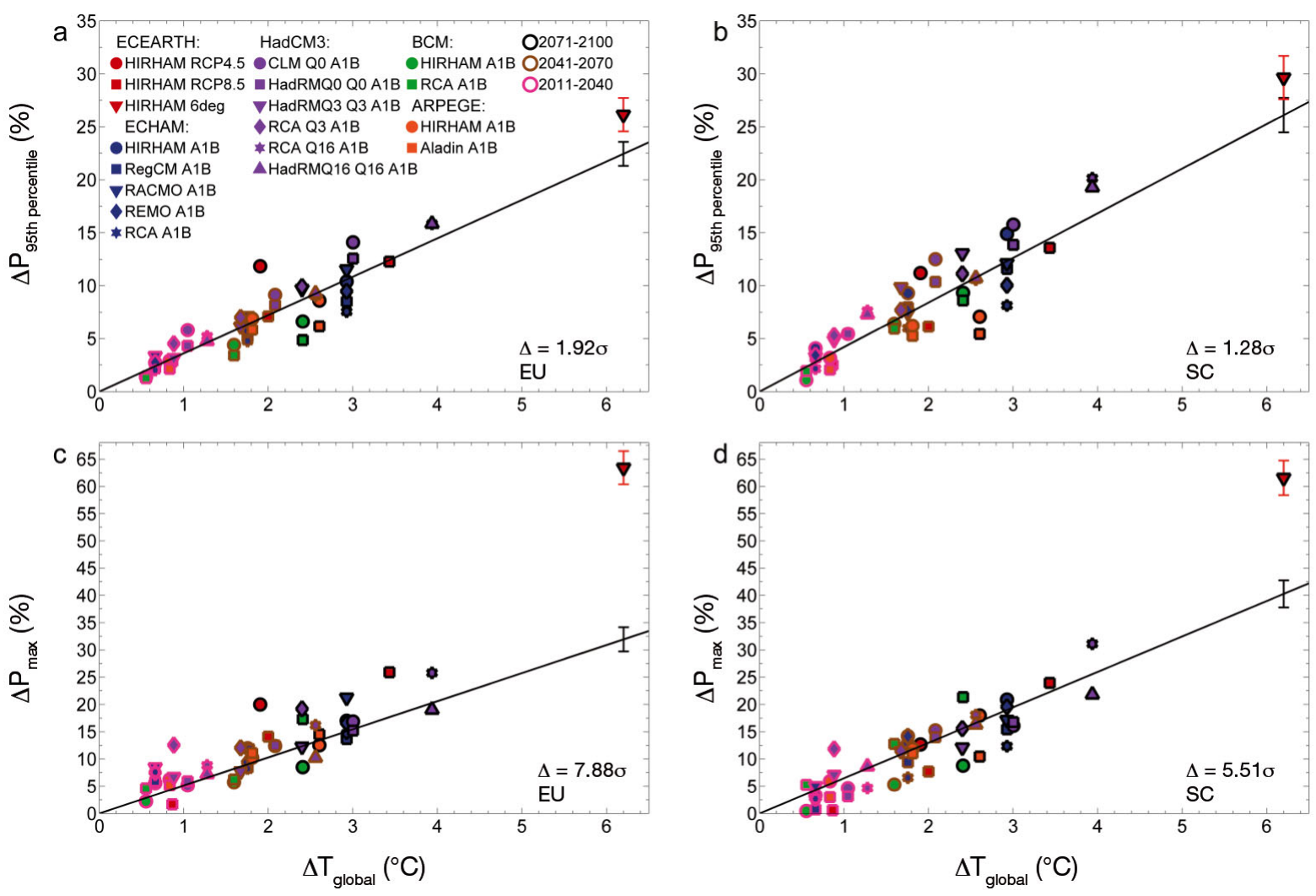

Fig. 7. Change in extreme daily precipitation: $(a, b)$ 95th percentile and $(c, d)$ maximum value for 8 European regions combined $\left(E U_{i} a, c\right)$ and Scandinavia $\left(S_{i} b_{1} d_{i}\right.$ see Fig. 4$)$ for all future time slices of all the ENSEMBLES models and for various HIRHAM runs. See text in Section 2.2 for an explanation of the error bars and the $\Delta$ values

changes in extreme precipitation (Fig. 7a,b), represented by the 95th percentile, scale well with the change in global mean temperature $(|\Delta|$ less than $2 \sigma)$ and the set of regional model simulations. Looking at the maximum precipitation values (Fig. $7 \mathrm{C}, \mathrm{d}$ ), the $6^{\circ} \mathrm{C}$ simulation is indeed significantly above the line $(|\Delta|$ much larger than $2 \sigma$ ), indicating that the change in very high precipitation extremes may have a higherorder dependence on global temperature change. This would seem reasonable; however, it cannot be 
immediately excluded that this deviation happens by chance, and is an issue for further investigation.

In order to study even larger precipitation extremes, we performed pointwise fits of the 30 annual maxima of daily precipitation in each grid point of each period to Gumbel functions. The fits are linear in the precipitation values, meaning that area-averaged extremes will correspond to Gumbel distributions with the area-averaged parameters. We therefore performed averages of the Gumbel parameters over the same European sub-regions as above, and analysed 13 ENSEMBLES models as well as the extra HIRHAM5 simulations. Through fitted parameters for both control and future periods, it is easy to calculate the future return period of the amount corresponding to any chosen return period in the current climate.

We show the changes of Gumbel parameters in Fig. 8, where a linear relationship corresponding to pattern scaling is generally plausible for the many simulations. However, the decisive scaling parameter $\beta$ for the $6^{\circ} \mathrm{C}$ simulation is above the line, in particular for the pan-European case (Fig. 8c) with a distance above $5|\Delta|$, and $\mu$ (average annual maximum daily precipitation) is significantly below the line. The future return period behaves in a roughly expo-
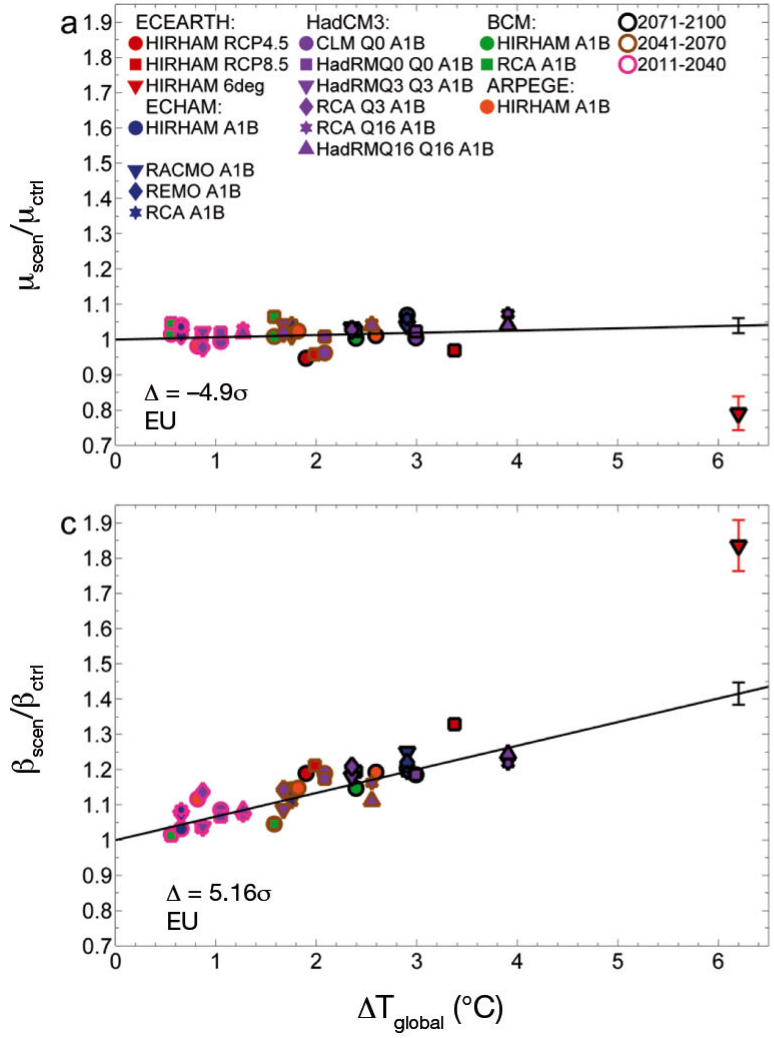

nential way as a function of the Gumbel parameters. For return times $t_{\mathrm{c}}$ and $t_{\mathrm{s}}$ for some extreme in a set of control and scenario experiments corresponding to the same amount of precipitation, and for these times much larger than $1 \mathrm{yr}$, the Gumbel distribution shows

$$
\ln \left(\frac{t_{\mathrm{s}}}{t_{\mathrm{c}}}\right) \cong \frac{\mu_{\mathrm{s}}-\mu_{\mathrm{c}}}{\beta_{\mathrm{s}}}+\left(\frac{\beta_{\mathrm{s}}-\beta_{\mathrm{c}}}{\beta_{\mathrm{s}}}\right) \ln t_{\mathrm{c}}
$$

In the present case, $\beta_{\mathrm{s}}$ is not considerably different from $\beta_{\mathrm{c}}$ (Fig. 8). This means that future return times of amounts corresponding to fixed return times in the present climate will behave roughly exponentially in global warming, with the $\beta$ parameter behaviour becoming increasingly dominant for large return times. This is confirmed when actually plotting $\ln \left(\frac{t_{\mathrm{s}}}{t_{\mathrm{c}}}\right)$ for the experiments for different presentclimate return times (not shown).

\section{DISCUSSION AND CONCLUSION}

In order to assess the representativeness of a single $6^{\circ} \mathrm{C}$ high-resolution simulation covering Europe, we have investigated whether pattern scaling holds for
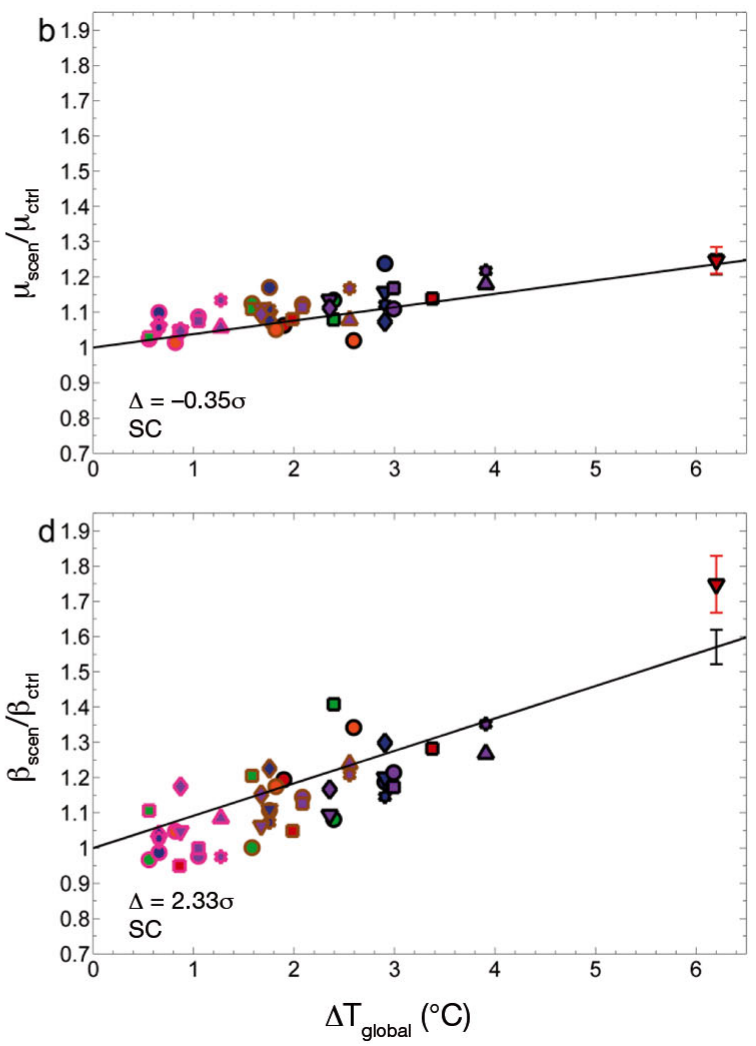

Fig. 8. Ratio of future Gumbel parameters $(\mathrm{a}, \mathrm{b}) \mu$ (average daily maximum precipitation) and (c,d) $\beta$ (scaling parameter) as a function of global warming, calculated for 8 European regions combined (EU; a,c) and Scandinavia (SC; b,d) (see Fig. 4). See text in Section 2.2 for an explanation of the error bars and the $\Delta$ values 
selected variables simulated with regional climate models over Europe. As already mentioned, basing a study of future climate on a single simulation is usually not enough for a robust analysis, as model scatter is quite large. We addressed this issue by an ensemble approach wherein we used multi-model spread from results provided by a coordinated experiment not specifically aimed at demonstrating or addressing pattern scaling issues. Within the spread defined by the multi-model ensemble, we find that averagebased parameters over Europe and Scandinavia, such as seasonal mean temperature and precipitation, clearly exhibit a fairly linear pattern scaling behaviour. Such a scaling approximately holds even for some extremes, like the 95th percentile of daily precipitation, and the $30 \mathrm{yr}$ return values of daily maximum temperature. This indicates that the $6^{\circ} \mathrm{C}$ simulation presented here in some detail is not an outlier with respect to these fields, and can be seen as representative of what would have been the general outcome, had many more models been applied and used to assess the changes in climatic conditions under such an extreme scenario.

Even for parameters extracted from Gumbel fits to annual extremes of daily precipitation, proportionality to global warming cannot be dismissed. There are, however, indications that linearity breaks down for the very highest extremes as seen in the plots of 30 yr daily precipitation return values and the Gumbel scaling parameter for annual extremes. More simulations with a strong forcing must be made before we would be able to test whether this is a general feature of strong-forcing simulations, or whether it is due to the specific simulation analysed here.

We expect that pattern scaling may fail, for example for snow cover or other parameters that depend on threshold values, like frost day frequency. For a given location, any threshold will be either exceeded or not, and therefore a gradual change with gradual global warming is only realistic when the temporal and/or spatial spread of the quantity in question is large. However, those cases are beyond the scope of the present study. The fact remains that - when taking the various uncertainties into account-many changes, even under what may be considered as an extreme scenario, are well characterized by linear extrapolations based on global temperature increase from combinations of less extreme climate scenarios. This indicates that, to a first order, adaptation measures aiming at planning for the unlikely but still possible high-end scenarios could benefit from simple extrapolations of existing knowledge. This will also allow the identification of priorities, as the relative importance of impacts from different kinds of events such as extreme rainfall vs. storm floods can be addressed in such a way that the likelihood of the occurrence of one extreme relative to the other can be addressed; this can help designing strategies to cope with these changes.

We do note, however, that the forcing used to drive the EC-Earth global model only accounts for 1 atmospheric forcing, $\mathrm{CO}_{2}$, while all other simulations also include different greenhouse gases and more importantly aerosols. The forcing from aerosols is spatially much more inhomogeneous than $\mathrm{CO}_{2}$ forcing, and therefore 1 global scaling parameter is expected to be insufficient in the case where both kinds of forcing are important and being considered. Given the regional loading of aerosols, one could speculate that the $6^{\circ} \mathrm{C}$ results could turn out differently if aerosols had been considered. Certainly one would expect to see some effects of modified cooling if this method was applied over a region with strong aerosol loading under present-day conditions.

The conclusions of the study presented here could be strengthened by adding additional high-end simulations corresponding to global warming of $4-6^{\circ} \mathrm{C}$, but so far such simulations are rare. With the CORDEX initiative, the successor of ENSEMBLES, we believe that several dynamical downscaling simulations of relatively high-end scenarios will soon become available, allowing for an extension of the present study. The CORDEX simulations are based on the CMIP5 runs, and as shown in Fig. 2, several of the RCP8.5 simulations reach a global mean temperature change of 3.5 to $6.5^{\circ} \mathrm{C}$ towards the end of the century. This could add points to the graphs presented here, which are more or less blank for global temperature change higher than $4^{\circ} \mathrm{C}$. Although not all of the CMIP5 simulations will be downscaled, several of them will most likely be downscaled using a series of different RCMs, which again would add to the robustness of the conclusions made from a study like this. Like the ENSEMBLES simulations, the CORDEX simulations are on a standardised integration area and horizontal resolution, making them ideal for a similar study.

It should be kept in mind that not all of the CMIP5 models appear to be consistent with the most recent warming, and model bias may in some cases result in a tendency to give temperature projections that are too high, particularly in the warm seasons. The fact that CMIP5 models with high-end warming or simulations going beyond 2100 are quite different in their response to radiative forcing suggests that an unrealistic closure of the atmospheric water budget could be re- 
sponsible at least partly for this behaviour. Otherwise, there is a possibility that artificial, non-radiative forcings have been introduced (Liepert \& Lo 2013), undermining confidence in the realism of attainment of high-end warming. Furthermore, the possibility of instances of abrupt system changes in any of these simulations (e.g. shut-down of the thermohaline circulation, shift in the North Atlantic storm track, change in dominant phase of the North Atlantic Oscillation) could yield non-linear changes across Europe. Such issues need to be addressed if the analysis presented here is to be used to draw conclusions more generally about extrapolation (using pattern scaling based on GCMs) into a very warm era.

Acknowledgements. The present study was funded by a grant from the Danish Council for Strategic Research for the project Centre for Regional Change in the Earth System (CRES; www.cres-centre.net) under contract no: DSF-EnMi 09-066868. The ENSEMBLES data used in this study were produced by the EU FP6 project ENSEMBLES. The transient RCP8.5 HIRHAM5 simulation was produced in the EU FP7 ClimateCost project. We acknowledge the World Climate Research Programme's Working Group on Coupled Modelling, which is responsible for CMIP, and we thank the relevant climate modelling groups for producing and making available their model output. For CMIP, the US Department of Energy's Program for Climate Model Diagnosis and Intercomparison provides coordinating support and led development of software infrastructure in partnership with the Global Organization for Earth System Science Portals.

\section{LITERATURE CITED}

Anderson K, Bows A (2011) Beyond 'dangerous' climate change: emission scenarios for a new world. Philos Trans R Soc Lond A Math Phys Eng Sci 369:20-44

> Betts RA, Collins M, Hemming DL, Jones CD, Lowe JA, Sanderson MG (2011) When could global warming reach $4^{\circ} \mathrm{C}$ ? Philos Trans R Soc Lond A Math Phys Eng Sci 369: 67-84

> Boberg F, Christensen JH (2012) Overestimation of Mediterranean summer temperature projections due to model deficiencies. Nat Clim Change 2:433-436

> Christensen JH, Boberg F (2012) Temperature dependent model deficiencies affect CMIP5 multi model mean climate projections. Geophys Res Lett 39:L24705, doi: 10.1029/2012GL053650

Christensen JH, Christensen OB (2007) A summary of the PRUDENCE model projections of changes in European climate by the end of this century. Clim Change 81:7-30

Christensen JH, Kjellström E, Giorgi F, Lenderink G, Rummukainen $M$ (2010) Weight assignment in regional climate models. Clim Res 44:179-194

Christensen OB, Drews M, Christensen JH, Dethloff K, Ketelsen K, Hebestadt I, Rinke A (2006) The HIRHAM regional climate model version $5(\beta)$. Tech Rep 06-17, Danish Meteorological Institute, Copenhagen

> Claussen M, Mysak L, Weaver A, Crucifix M and others (2002) Earth system models of intermediate complexity: closing the gap in the spectrum of climate system models. Clim Dyn 18:579-586

Collins M, Knutti R, Arblaster J, Dufresne JL and others (2013) Long-term climate change 2013: projections, commitments and irreversibility. In: Stocker TF, Qin D, Plattner GK, Tignor M and others (eds) Climate change 2013: the physical science basis. Contribution of Working Group I to the Fifth Assessment Report of the Intergovernmental Panel on Climate Change. Cambridge University Press, Cambridge

Hazeleger W, Wang X, Severijns C, Ştefănescu S and others (2012) EC-Earth V2.2: description and validation of a new seamless Earth system prediction model. Clim Dyn 39:2611-2629

Houghton JT, Ding Y, Griggs DJ, Noguer M and others (eds) (2001) Climate Change 2001: the scientific basis. Contribution of Working Group I to the Third Assessment Report of the Intergovernmental Panel on Climate Change. Cambridge University Press, Cambridge

Huntingford C, Cox PM (2000) An analogue model to derive additional climate change scenarios from existing GCM simulations. Clim Dyn 16:575-586

> Joshi M, Hawkins E, Sutton R, Lowe J, Frame D (2011) Projections of when temperature change will exceed $2{ }^{\circ} \mathrm{C}$ above pre-industrial levels. Nat Clim Change 1:407-412

Katsman CA, Sterl A, Beersma J, van den Brink HW and others (2011) Exploring high-end scenarios for local sea level rise to develop flood protection strategies for a lowlying delta - the Netherlands as an example. Clim Change 109:617-645

Kjellström E, Boberg F, Castro M, Christensen JH, Nikulin G, Sánchez E (2010) Daily and monthly temperature and precipitation statistics as performance indicators for regional climate models. Clim Res 44:135-150

> Lambert FH, Harris GR, Collins M, Murphy JM, Sexton DMH, Booth BBB (2013) Interactions between perturbations to different Earth system components simulated by a fully-coupled climate model. Clim Dyn 41:3055-3072

Le Quéré C, Moriarty R, Andrew RM, Peters GP and others (2014) Global carbon budget 2014. Earth Syst Sci Data Discuss 7:521-610

> Liepert BG, Lo F (2013) CMIP5 update of 'Inter-model variability and biases of the global water cycle in CMIP3 coupled climate models'. Environ Res Lett 8:029401, doi: 10.1088/1748-9326/8/2/029401

- Lustenberger A, Knutti R, Fischer EM (2014) The potential of pattern scaling for projecting temperature-related extreme indices. Int J Climatol 34:18-26

Mitchell TD (2003) Pattern scaling - an examination of the accuracy of the technique for describing future climates. Clim Change 60:217-242

Moss RH, Edmonds JA, Hibbard KA, Manning MR and others (2010) The next generation of scenarios for climate change research and assessment. Nature 463:747-756

Nakićenović N, Davidson O, Davis G, Grübler A and others (2000) Special Report on Emissions Scenarios. A Special Report of Working Group III of the Intergovernmental Panel on Climate Change. Cambridge University Press, Cambridge

> New M (2011) Four degrees and beyond: the potential for a global temperature increase of four degrees and its implications. Philos Trans R Soc Lond A Math Phys Eng Sci 369:4-5

New M, Liverman D, Schroeder H, Anderson K (2011) Four degrees and beyond: the potential for a global tempera- 
ture increase of four degrees and its implications. Philos Trans R Soc Lond A Math Phys Eng Sci 369:6-19

Peters GP, Andrew RM, Boden T, Canadell JG and others (2013) The challenge to keep global warming below $2{ }^{\circ} \mathrm{C}$. Nat Clim Change 3:4-6

Ruosteenoja K, Tuomenvirta H, Jylhä K (2007) GCM-based regional temperature and precipitation change estimates for Europe under four SRES scenarios applying a superensemble pattern-scaling method. Clim Change 81: 193-208

Sanderson MG, Hemming DL, Betts RA (2011) Regional temperature and precipitation changes under high-end $\left(\geq 4^{\circ} \mathrm{C}\right)$ global warming. Philos Trans R Soc Lond A Math Phys Eng Sci 369:85-98

Santer BD, Wigley TML, Schlesinger ME, Mitchell JFB (1990) Developing climate scenarios from equilibrium GCM results. Report, Max Planck Institut für Meteorologie, Hamburg

Shiogama H, Emori S, Takahashi K, Nagashima T, Ogura T, Nozawa T, Takemura T (2010a) Emission scenario dependency of precipitation on global warming in the MIROC3.2 model. J Clim 23:2404-2417

Shiogama H, Hanasaki N, Masutomi Y, Nagashima T and others (2010b) Emission scenario dependencies in climate change assessments of the hydrological cycle. Clim Change 99:321-329

Sloth Madsen M, Maule CF, MacKellar N, Olesen JE, Christensen JH (2012) Selection of climate change scenario data for impact modelling. Food Addit Contam A 29:

Submitted: May 12, 2014; Accepted: January 15, 2015
$1502-1513$

Solomon S, Qin D, Manning M, Chen Z and others (eds) (2007) Contribution of Working Group I to the Fourth Assessment Report of the Intergovernmental Panel on Climate Change. Cambridge University Press, Cambridge

Stocker TF (2013) The closing door of climate targets. Science 339:280-282

Stocker TF, Qin D, Plattner GK, Tignor M and others (eds) (2013) Climate Change 2013: the physical science basis. Contribution of Working Group I to the Fifth Assessment Report of the Intergovernmental Panel on Climate Change. Cambridge University Press, Cambridge

Stott P, Good P, Jones G, Gillett N, Hawkins E (2013) The upper end of climate model temperature projections is inconsistent with past warming. Environ Res Lett 8: 014024, doi:10.1088/1748-9326/8/1/014024

> Taylor KE, Stouffer RJ, Meehl GA (2012) An overview of CMIP5 and the experiment design. Bull Am Meteorol Soc 93:485-498

van der Linden P, Mitchell JFB (eds) (2009) ENSEMBLES: climate change and its impacts: summary of research and results from the ENSEMBLES project. Met Office Hadley Centre, Exeter

Vautard R, Gobiet A, Sobolowski S, Kjellström E and others (2014) The European climate under a $2^{\circ} \mathrm{C}$ warming. Environ Res Lett 9:034006, doi:10.1088/1748-9326/9/3/034006

Wilby RL, Nicholls RJ, Warren R, Wheater HS, Clarke D, Dawson RJ (2011) Keeping nuclear and other coastal sites safe from climate change. Civ Eng 164:129-136

Proofs received from author(s): April 9, 2015 